\title{
Los discursos sobre la participación política en el proceso de paz de Colombia
}

\section{Discourses on Political Participation in the Colombia's Peace Process}

\author{
Jerónimo Ríos ${ }^{1}$ \\ Universidad EAN (Colombia) \\ Heriberto Cairo ${ }^{2}$ \\ Universidad Complutense de Madrid (España)
}

Recibido: 01-11-17

Aprobado: 14-01-18

\section{Resumen}

Uno de los aspectos más importantes del Acuerdo de Paz suscrito en noviembre de 2016 entre el Gobierno de Colombia y la guerrilla de las FARCEP es lo que concierne a la participación política. Sin embargo, ¿qué se entiende por participación política? Este trabajo muestra, a partir de un análisis del discurso con algunos de los protagonistas directos del Acuerdo, que existen diferentes maneras de entender el alcance y sentido de aquélla en función del actor que lo interpreta. Así, la participación política puede suponer un ejercicio de descentralización territorial, nuevas formas de participación ciudadana o la posibilidad de transformar a la guerrilla en partido político. Sin embargo, no todas las visiones ofrecidas contemplan tales posibilidades, hasta el punto de proponerse, en algunos casos, que sean las próximas elecciones presidenciales de 2018 el verdadero escenario en el que discuta la continuidad misma del Acuerdo.

Palabras-clave: Acuerdo de Paz, análisis del discurso, Colombia, participación política.

\footnotetext{
${ }^{1}$ (jriossie@universidadean.edu.co). Doctor en Ciencias Políticas de la Universidad Complutense de Madrid y Profesor Asociado de la Facultad de Administración, Finanzas y Ciencias Económicas de la Universidad EAN, Colombia

2 (hcairoca@cps.ucm.es). Doctor en Ciencias Políticas y Sociología de la Universidad Complutense de Madrid y Profesor Titular de la Facultad de Ciencias Políticas y Sociología de la Universidad Complutense de Madrid, España.
} 


\begin{abstract}
One of the most important aspects of the Peace Agreement signed in November of 2016 between the Government of Colombia and the FARC guerrilla is what concerns political participation. However, what is meant by political participation? This paper shows, from a frame-analysis with some of the main actors of the Agreement, that there are different ways of understanding its scope and meaning of the one, depending on the actor who interprets it. Thus, political participation implies an exercise of territorial decentralization, new forms of citizen participation or the option of transforming the guerrilla into a political party. However, not all the views offered contemplate such possibilities, to the point of proposing, in some cases, that the next presidential election of 2018 is the true scenario in which it discusses the continuity of the Agreement.
\end{abstract}

Key-words: Peace Agreement, Frame Analysis, Colombia, Political Participation.

\title{
1. Introducción
}

El Acuerdo de Paz suscrito entre la guerrilla de las FARC-EP y el Gobierno colombiano, suscrito el pasado 24 de noviembre de 2016, supone no solo dejar atrás más de medio siglo de una confrontación directa que ha dejado consigo 60.000 desaparecidos, 30.000 secuestros, 13.000 víctimas de violencia sexual y 220.000 muertes (Centro Nacional de Memoria Histórica, 2013). El Acuerdo de Paz representa un nuevo escenario de transformación estructural, territorial e institucional del Estado de Colombia y tiene ante sí la necesidad de superar diferentes barreras económicas, sociales, políticas y culturales que deben dejar atrás los condicionantes que durante tanto tiempo sostuvieron la violencia (Ríos, 2017).

Entre estas cuestiones, y de acuerdo a lo que proponen Galtung (1969; 1998) o Lederach (2005), la resolución, la reconstrucción y la reconciliación exigen de todo Acuerdo de Paz elementos de reconocimiento mutuo entre las partes que estuvieron enfrentadas bajo la violencia, así como de estas con la población civil y viceversa. Es así que ganan peso específico en todos los procesos de negociación pacífica de conflictos armados cuestiones tales como la justicia transicional, la dejación de las armas, las reformas electorales o las comisiones de la verdad (Instituto Kroc, s.f.; Fisas, 2002; Miall et al., 2015). Junto a éstas, una de las más importantes, si no la más importante es la participación política (Bencardino, 2014; Taylor, 2016). 
Es por ello que más allá de preguntarse sobre qué tipo(s) de participación política propone el Acuerdo de Paz como forma de superación del conflicto, lo que se plantea este trabajo es conocer cómo las elites políticas entienden y sustantivan dicho concepto. Es decir, qué narrativas se construyen a partir del Acuerdo con la guerrilla en relación con la participación ${ }^{3}$.

Así, las siguientes páginas invitan a comprender cómo se interpreta la participación y cuáles son sus consecuencias políticas. Al respecto, se consideró que lo importante era recoger los relatos de los actores, y por ello es que se realizaron entrevistas semiestructuradas en profundidad entre los protagonistas del proceso de paz y algunos de sus más perseverantes opositores. En concreto se entrevistó a Sergio Jaramillo (Alto Comisionado de Paz del Gobierno colombiano para el diálogo de paz con las FARC-EP en La Habana), Carlos Rojas (Mayor General responsable del Comando Conjunto de Monitoreo y Verificación de los Acuerdos y miembro del Comando Estratégico de Transición para el posconflicto armado), Ricardo Restrepo (Mayor General y Subdirector General de la Policía Nacional de Colombia), Luciano Marín Arango, alias "Iván Márquez" (Comandante del Bloque Caribe de las FARC-EP, miembro del miembro del Secretariado y jefe del equipo negociador de las FARCEP con el Gobierno colombiano en La Habana), Seusis Pausias Hernández, alias "Jesús Santrich" (Miembro del Estado Mayor Central de las FARC-EP, miembro del equipo negociador de la FARC-EP con el Gobierno colombiano en La Habana), Humberto de la Calle (exministro y exvicepresidente de la República, Jefe del equipo negociador del Gobierno con las FARC-EP), Marta Lucía Ramírez (exministra de Comercio Exterior y exministra de Defensa, líder del Partido Conservador y opositora al Acuerdo de Paz) y Alejandro Ordóñez (exProcurador General de la Nación y opositor al Acuerdo de Paz).

Una vez realizadas las entrevistas procedimos a realizar un análisis semiológico que permitiera fijar las narrativas existentes. Es evidente que las de estas elites políticas no son las únicas narrativas posibles, y que en la medida en que todos los colombianos son actores del proceso, de forma más o menos directa o indirecta, habría posiblemente más narrativas sobre la participación política, de modo que se podrían discernir más conjuntos discursivos que los que se han señalado sobre el conflicto y el proceso de paz, en general. Para extender estos límites de la investigación habría que diseñar una serie de grupos de discusión que comprendiesen todo el tejido social colombiano, siendo ésta una investigación que se haría en una segunda etapa.

\footnotetext{
${ }^{3}$ En otro lugar hemos comenzado a tratar las narrativas sobre el concepto de paz territorial resultantes del proceso de paz (Cairo et al., 2018)
} 


\section{Participación política y posconflicto armado}

Uno de los principales retos a la hora de desactivar un conflicto armado como el colombiano pasa por encontrar los mecanismos que inviten a poner fin a la violencia como forma inherente de la resolución del conflicto e institucionalizar éste dentro de las normas democráticas (Ríos, 2017b). Foucault (1976) señalaba que la política es la continuación de la guerra por otros modos, modificando así el sentido de la famosa aseveración atribuida a Clausevitz (1832), y permitiendo así comprender la continuidad existente entre la guerra y la paz, que es mucho mayor de lo que se suele pensar.

En cualquier caso, la dimensión política de un escenario de posconflicto armado se torna especialmente compleja en el momento en el que ésta exige de cierta transformación de las estructuras del Estado. Ello, en tanto que debe integrar opciones políticas que hasta el cese de un conflicto armado únicamente habían sido expresadas a través de la violencia. De hecho, desde la resolución de conflictos y la investigación para la paz, ésta es una dimensión especialmente atractiva para la disciplina (Harto, 2004; Miall et al., 2015) en tanto que han de implementarse una serie de medidas destinadas a garantizar el tránsito de las armas a las urnas de parte de los grupos armados. Una cuestión especialmente importante en las negociaciones de paz entre grupos armados y Gobiernos, sobre todo, si se tiene en consideración que desde el fin de la Segunda Guerra Mundial la forma más habitual de resolución de conflictos ha sido el diálogo (Harbom, Högbladh y Wallesteen, 2006), siendo una tendencia especialmente notoria en el siglo XXI (Mason et al., 2007).

Es decir, la ausencia de derrota que acompaña a un conflicto armado resuelto por la vía negociada supone per se la necesidad de trascender la clásica noción de entender la paz como la ausencia de guerra (Galtung, 1969; Lederach, 1997) y, más bien, interpretar que la misma, una vez finalizada la violencia, exige de transformaciones estructurales que intervengan sobre los factores que soportaron durante tiempo atrás dicha violencia (Galtung, 1969; Sandole y Sandole, 1987; Burton, 1990; Dukes, 1999).

Así, uno de esos elementos nucleares es la dimensión política y muy particularmente, lo relativo a la participación. Esto, en la medida en que, como propone Becker (1999) resulta imprescindible para garantizar unos mínimos de estabilidad política y en tanto que, de acuerdo con Jarstad y Sisk (2008), deviene indisociable frente a cualquier intento efectivo de construcción de paz.

Con base en lo expuesto Ugarriza (2013), transformar la dimensión política de un contexto de violencia en aras de un escenario de construcción de paz, entre otros, exige intervenir sobre tres elementos que gravitan a su vez en torno al concepto de participación: 1) nuevos diseños institucionales, 2) nuevas formas de participación ciudadana y 3 ) garantías plenas frente al ejercicio de reincorporación a la vida civil de los excombatientes. 
Autores como Wallesteen (2010) o Guelke (2012), por señalar dos ejemplos entre una amplia literatura científica, coinciden también en señalar cómo la superación de un conflicto armado demanda de nuevos escenarios institucionales que promuevan dichas nuevas participaciones políticas y representaciones, incluso, por medio de arreglos electorales o constitucionales, en tanto que resultan necesarios si de garantizar la plena transformación del conflicto de enemigos a adversarios se trata (Fisas, 2004; Harto, 2013).

Por otro lado, la transformación sistémica debe tener un acompañamiento, tanto en el nivel grupal que efectivamente se desmoviliza, como en el mismo individuo, de modo que se han de facilitar dinámicas que institucionalicen, reconozcan, visibilicen y legitimen las nuevas prácticas, narrativas y discursos políticos pacíficos y democráticos de quienes en el pasado entendían el conflicto en clave de violencia (Berdal y Ucko, 2009). También se ha de favorecer transformaciones en el nivel individual que acompañen no solo el cambio en los imaginarios políticos de los excombatientes en clave de aprendizaje democrático. Esto, porque conviene recordar que el excombatiente ha de transformarse en ciudadano democrático (Denissen, 2010), lo cual igualmente exige de acciones y lecciones de la sociedad civil en términos de reconciliación política y superación de la otrora violencia cultural (Galtung, 1985; Lederach, 1997; Jiménez, 2002).

Finalmente, tanto un nuevo diseño institucional como una efectiva reincorporación política tienen que orientarse hacia la producción de nuevas ciudadanías y nuevas formas de participación. Es decir, tienen que tener cabida, lato sensu, otro tipo de expresiones, ya sean organizacionales, sociales, de protesta social o dentro del propio diseño y funcionamiento democrático a efectos de conferirle mayores dosis de estabilidad y legitimidad (PNUD, 2004).

Es por todo lo anterior que el Acuerdo de Paz, en el caso de las FARCEP con el Estado colombiano, tiene que entenderse como un impulso para transformar no solo el sistema político, sino que igualmente repercute en la posibilidad de cambiar profundamente la ciudadanía colombiana. Una ciudadanía que, como se verá con posterioridad, puede experimentar el paso de una realidad desprovista de facto de derechos participativos dentro del sistema político democrático (Bushnell, 2007; Bejarano, 2011), hacia una sociedad provista de nuevas posibilidades. Ello, en tanto que la participación política, aparte de poner fin a un discurso político durante décadas, acompañado de las armas, permite la posibilidad de construir una ciudadanía multicultural que reconozca identidades y derechos étnicos en pie de igualdad de oportunidades y capacidades (Kimlycka, 1996); pero también inspirando nuevas posibilidades para una ciudadanía deliberativa, a partir de los reconocimientos, acuerdos, intercambios e integración de decisiones que representa el acuerdo (Habermas, 1987, 1999). 


\section{Narrativas y entrevistas en la investigación politológica}

Hablar de narrativas como instrumento de análisis del discurso supone hacer referencia a un elenco de argumentaciones a partir de las cuales se explica la comprensión de un fenómeno. De este modo, lo que este trabajo aborda es precisamente entender qué y cómo se entiende la participación política, particularmente de las FARC-EP, a tenor del Acuerdo de Paz suscrito con el Estado colombiano a finales del año 2016. Y es que, de acuerdo con Lanza (2017), recurrir a las narrativas permite construir un conocimiento sistemático sobre el que se interpretan y representan procesos políticos, en este caso, a partir de los relatos que construyen las elites alrededor del Acuerdo de paz, y que terminan por nutrir de significado un concepto como es el de participación política.

Sin embargo, tales relatos, conforme lo que proponen Barzelay y Cortázar (2004), no deben reducirse a dimensiones temporales restringidas, como pudiera suponer el propio fin del conflicto y lo que éste supone, sino que los testimonios cómo se plantean, responden a lecturas que se remontan a lo largo del tiempo y cuya confluencia, en última instancia, permite la creación de un trama en la que se contrasta el objeto de análisis, siempre, a partir de la interacción entre las conjeturas propias del investigador y la evidencia relativa del fenómeno estudiado.

En todo caso estas narrativas están cargadas de ideología, por la propia dimensión política del objeto de estudio. Entendiendo el término en el sentido que lo hace Geertz (1987: 178), en tanto que son "mapas de una realidad social problemática y matrices para crear una conciencia colectiva". Es decir, las narrativas se representarían cargadas de una ideología que define u oscurece categorías sociales, estabiliza o perturba expectativas sociales, mantiene o mina normas sociales, fortalece o debilita el consenso social y alivia o exacerba las tensiones sociales (Ariño, 1997; Van Dijk, 2005).

En definitiva, se trata de saber qué entienden las elites entrevistadas como participación a partir del Acuerdo de Paz, y qué representa ésta en la transformación de estructuras políticas sobre: las que se fundamenta el posconflicto armado colombiano. Asimismo, y de acuerdo con Roth (2010), ello ha de inscribirse sobre la base de un marco conceptual y de categorías de análisis que se centrarán en visibilizar las lecturas que se hacen sobre 1) los cambios institucionales del Estado, especialmente, entendiendo la participación política en clave territorial (descentralización); 2) la participación política electoral, atendiendo al tránsito hacia las urnas que deben experimentar las FARC-EP al dejar de ser grupo guerrillero; 3) y de qué modo lo anterior influye sobre un sentido de la participación política no solo electoral, y no solo de los excombatientes, incidiendo directamente en la participación ciudadana y en nuevas posibles categorías de ciudadanía. 
A partir de lo anterior, recurriendo a Edelman (1991), se podría señalar cómo es en los conflictos del significado dónde se verdaderamente tiene lugar la política. Es decir, en el lenguaje político presente en las narrativas empleadas se podría observar de qué modo se construyen las creencias sobre aliados y enemigos políticos, la manera de gestionar el sentido de la participación, los diversos grados de legitimación del sistema, las lecturas reconstructivas del pasado y sus proyecciones hacia el futuro, además del lenguaje de la promesa en toda su complejidad y la definición recíproca de subjetividad y realidad como instrumentos desde los que describir objetivamente lo que se entiende por participación una vez se implemente el Acuerdo de Paz en Colombia (Edelman, 1991; Van Dijk, 2004).

En cualquier caso, las entrevistas en profundidad utilizadas no homogeneizan las narrativas de los entrevistados, que pueden asumir algunas que son de hecho antitéticas, por lo que es muy importante hacer un análisis que no parta de preconceptos de los autores (Prokkola, 2014). Asimismo, quedaría señalar que las entrevistas tuvieron lugar entre el 10 de febrero y el 13 de marzo de 2017. Todas se celebraron en diferentes lugares de Bogotá y tuvieron una duración de entre 30 y 90 minutos. De igual modo fueron grabadas y en todas se advirtió que su contenido podría ser citado en contextos académicos, a lo que prestaron su consentimiento los entrevistados.

\section{La participación política en el Acuerdo de Paz}

El Acuerdo de Paz suscrito entre las FARC-EP y el Gobierno colombiano entiende la participación política como la facultad que tienen todas las personas de intervenir en las decisiones que las afectan, invocando la necesidad de promover una democracia participativa que trascienda más allá de la mera representación política y participación electoral. Es por esto que se reivindica un sentido jurídico ya reconocido en la Ley 134 de 1994 de Participación Política, pero que, en la práctica y no solo por el conflicto armado interno, ha sido desdibujado en buena parte del territorio colombiano.

Es por eso que el Acuerdo, reconociendo expresamente tales limitaciones, invoca la necesidad de impulsar transformaciones políticas que más allá de la participación directa electoral, se traduzcan en nuevos roles ciudadanos en cuanto a planeación, implementación, evaluación o control de programas y políticas públicas.

Dentro de los tres niveles de participación política más relevantes cabe destacar los siguientes: 
- La incorporación de una metodología PDET - Planes de Desarrollo con Enfoque Territorial - que identifica casi 200 municipios rurales, fuertemente afectados por la violencia directa y la violencia estructural, que permite una mayor participación de estos en la planificación y diseño de políticas públicas que se orienten a mejorar las condiciones sociales y económicas de los mismos, a la vez que se impulsan proyectos económico de índole cooperativa sobre los que han de beneficiarse los excombatientes de la guerrilla.

- La creación de un Estatuto de Oposición desde el que se han de definir los lineamientos para el ejercicio de la oposición política, partidista y social, que además garantiza un sistema de seguridad conformado desde el Estado con el propósito de evitar cualquier tipo de violencia sobre los nuevos movimientos políticos que deben surgir tras el Acuerdo. Esto es, no solo un partido político de las FARC-EP, sino igualmente nuevas formas de movilización y protesta social.

- La creación de 16 circunscripciones transitorias especiales de paz que se reconocen como las zonas más afectadas y vulneradas por el conflicto colombiano para que de este modo tengan representación directa en el Congreso de la República. Una cuestión esta que permite problematizar, visibilizar y politizar aspectos estructurales y simbólicos que durante décadas fueron desatendidos por el Estado colombiano.

Estos tres aspectos incidirían en una participación política que no solo es electoral, y que en principio pluraliza y profundiza los aspectos democráticos del Estado colombiano; en tanto que resalta cómo la ciudadanía participativa resulta imprescindible de acuerdo a nuevos actores políticos y sociales que, asimismo, amplían la toma de decisiones, especialmente en el nivel local. De igual manera, de implementarse efectivamente lo acordado por FARC-EP y Gobierno colombiano, sería de esperar que se fortaleciesen los espacios de participación y activismo social, pero también en cuanto a la opinión pública, pues el Acuerdo prevé la presencia de las FARC-EP en radios comunitarias y de radiotelevisión pública con el propósito de tener una incidencia real para que los mecanismos de participación sean efectivos en el proceso de toma de decisiones.

Finalmente, todo lo anterior debiera inscribirse en entender la construcción de una paz estable y duradera, como la que sugiere el Acuerdo, con base en una ampliación de la inclusión democrática además de una cualificación de actores políticos y sociales en aras de permitir la emergencia de nuevas fuerzas y un enriquecimiento del debate y la deliberación democrática. 


\title{
5. Los discursos sobre la participación política en Colombia
}

En general, la participación política es uno de los ejes fundamentales en las narrativas sobre las oportunidades de transformación que prevé el Acuerdo de Paz, tanto entre quienes se encuentran a favor, como entre sus principales detractores. De hecho, un clivaje que ha marcado no solo el plebiscito del pasado octubre de 2016, sobre el que la sociedad colombiana debía decidir si respaldaba el primer acuerdo entre las FARC-EP y el Gobierno colombiano, sino que igualmente, como se verá con posterioridad, debe marcar, según algunos, el rumbo de las próximas elecciones presidenciales previstas para la primavera de 2018.

Para el conservadurismo y, por ende, para las posiciones más contrarias a la ventana de oportunidad política para las FARC-EP que representa el Acuerdo, su inclusión en política supone desdibujar el Estado de Derecho y las bases democráticas del mismo de acuerdo a tres argumentos fundamentales.

El primero de ellos pasaría por negar la posibilidad de participación política directa de aquellos que pertenecieron a la comandancia de la guerrilla recurriendo a una presunta lógica de la normativa propia del Derecho Internacional Humanitario:

\begin{abstract}
"Uno no puede estar satisfecho con que se inyecte a participar en política cuando se tiene un prontuario de crímenes de lesa humanidad tan grande como lo tienen muchos miembros de las FARC. Para mí, la participación política y el hecho que no haya habido ninguna justicia son los mayores reparos, y es que van de la mano, porque la Constitución colombiana prevé que quien haya sido condenado por cualquier tipo de delito, excepto los delitos políticos, no puede entrar a la política. Eso es lo que decía la Constitución y eso lo borraron en el acuerdo" (Entrevista a Marta Lucía Ramírez, 2017).
\end{abstract}

Un segundo argumento reduciría el hecho de que las FARC-EP participen en política a una suerte de entrega de la democracia que termina siendo más finalista que instrumental. Es decir, si bien la participación en política, por el propio funcionamiento de las normas de representación, no supone de manera determinista una transformación de las estructuras de Gobierno, posiciones como la que encabeza el exprocurador Alejandro Ordóñez señalarían cómo la participación en política de las FARC-EP, en el fondo, supone en sí misma una involución democrática:

\footnotetext{
“Allá le entrego la institucionalidad. Y desde luego, el manejo de las políticas públicas. El manejo del presupuesto público. El manejo de la representatividad política. Eso será la paz territorial” (Entrevista a Alejandro Ordóñez, 2017).
} 
De estas palabras, como de las anteriores de Marta Lucía Ramírez, se deduciría que el problema no reposa en que sean urgentes ciertas reformas que mejoren la calidad democrática del Estado colombiano, sino que sean las FARC-EP quienes puedan ser el motor de cambio de los mismos:

"Si en realidad el propósito hubiera sido generar prosperidad, generar desarrollo, hace presencia institucional, legitimar el Estado de derecho, con las políticas públicas, dirigir la inversión pública y la inversión social, eso no tendría por qué generar críticas de nuestra parte, pero eso no fue. Se nos va a convertir nuevamente en un narcoestado inviable. También, la entrega de la institucionalidad en esas zonas del país y de allí la amenaza a todo el proceso democrático del país, porque los millones de dólares que se esconden y que se van a incrementar con las FARC, con el narcotráfico y la minería ilegal van a amenazar nuestra democracia” (Entrevista a Alejandro Ordóñez, 2017).

Es decir, de acuerdo a estas posturas más reaccionarias no se aprecia una lectura del Acuerdo como un instrumento que garantice una mayor pluralidad - algo que en ninguna de las entrevistas se reconoce - sino que, todo lo contrario, la participación en política de las FARC-EP se presume que va a contribuir a una mayor desestabilización política. Tal vez, son concluyentes las siguientes palabras de Marta Lucía Jiménez advirtiendo, a tal efecto, de una mayor conflictividad social, posiblemente, en la medida en que, ante la ausencia de guerrilla, la bandera política de transformación social debería de inspirar nuevos movimientos sociales y grupos de interés. Sin embargo, lejos de entender esto como un avance democrático, la exministra de Defensa entiende la conflictividad como un camino inexorable hacia la "anarquía social":

"Flexibilizar tanto la entrada de las FARC a la política, sin mayor compromiso en cuanto a que no haya una ideología ni una organización de partido ni un trabajo político como corresponde y, al contrario, dentro de esta flexibilidad, y con el pretexto de que haya más participación ciudadana en la política, entonces lo que hicieron fue abrir un espacio gigantesco para la protesta social. El país ingenuamente compró, en un $50 \%$ por ciento, que la protesta social era sinónimo de una mejor democracia. Pero cuando la protesta social se trata de volver algo permanente y algo que está dirigido con una motivación política perversa que es hacer colapsar la institucionalidad y el Estado de derecho, me parece que ahí tenemos un riesgo terrible. No tengo ninguna duda que nos pueden llevar en la dirección de Venezuela, y eso es lo que tenemos que evitar (Entrevista a Marta Lucía Ramírez, 2017).

Una visión que nada tiene que ver con la de las FARC-EP, quienes entienden que la oposición política y la protesta social, por el contrario, deben ser reconocidas, integradas y normalizadas democráticamente por el avance democrático que suponen: 
"Insistimos mucho en el estatuto de la oposición, para acceder a las visiones y a las concepciones diferentes de las que se imponen desde el centro (...) En el punto de participación del acuerdo hay un sub-punto que deben desarrollar las comunidades, que es el estatuto de la oposición para el movimiento social. Eso no se podía pactar en la mesa, y entonces se dijo que se haría un escenario de participación política en el país, donde se iba a invitar a ese movimiento y organizaciones, los más representativos, para que organicen la normatividad de participación política y de garantías a la movilización. Esto está en trámite" (Entrevista a "Jesús Santrich).

"Hemos logrado que se reconozca el derecho a la oposición política de las organizaciones sociales de Colombia (...) Va a haber una reglamentación en esta materia y hemos pedido que sean las propias organizaciones sociales, las que discutan y también hagan una propuesta al Legislativo, para que se garantice el derecho a la oposición del movimiento social en Colombia" (Entrevista a "Iván Márquez", 2017).

También contrasta, frente a las visiones contrarias al Acuerdo de Paz, cómo la posición gubernamental normaliza la participación política y en ningún momento la entiende como un elemento sobre el que cuestionar la validez del mismo o, más allá, interpretarlo como una amenaza al sistema político colombiano. Lo anterior, porque de acuerdo con la participación política, el equipo negociador no reduce ésta a una cuestión estrictamente electoral y partidista como lo planteaban algunos de los anteriores entrevistados. Todo lo contrario, lato sensu, la participación política, principalmente, se entendería en términos de democracia local y aproximación a la ciudadanía, y también a las FARC-EP, de abrir la toma de decisiones en favor de aquellas comunidades que fueron más golpeadas por la violencia en Colombia:

"Un tercer elemento que pensaría yo que puede ser el más importante es la estructuración de los PDET alrededor de la participación muy intensa de las comunidades rurales, de las comunidades beneficiarias. Sobre participación venimos hablando en Colombia, desde hace años, con poco éxito. Dijéramos que hay ejercicios esporádicos y algunos bastante desarticulados, pero estos planes se basan, en primer lugar, en un ejercicio de priorización del gasto, hecho por las propias comunidades, las FARC desarmadas, dentro de esas comunidades, establecen los propósitos prioritarios de la acción de los planes de desarrollo" (Entrevista a Humberto de la Calle, 2017).

La anterior consideración es igualmente propuesta por Sergio Jaramillo, Alto Comisionado de Paz durante todo el proceso de diálogo con las FARC-EP, cuando señala que la participación política prevista en el Acuerdo, ante todo, debe invitar a resignificar la ciudadanía colombiana, tradicionalmente, como señalan Acemoglu, Robinson y Santos (2013) o Robinson (2016), ajena a la toma de decisiones y a cualquier atisbo de influencia en la planificación de políticas públicas: 
"La idea de paz territorial es cómo estructurar y articular esos procesos de participación, de planeación participativa, con respuesta eficaz del gobierno, y con un sentimiento de la gente de que tiene voz y se le tiene en cuenta" (Entrevista a Sergio Jaramillo, 2017).

Empero, quizá resulta más interesante la particular concepción que realiza cuando expresamente se refiere a cómo el interés de participación ciudadana, especialmente reivindicado por las FARC-EP, en ningún momento se torna problemático, sino que, más bien se entiende que deviene una necesidad estructural, de transformación del Estado, y no una concesión en beneficio de la guerrilla. Incluso, pudiera entenderse en algún momento de la entrevista que es precisamente, esa falta de participación política, tal y como en ocasiones han planteado trabajos como los de Pizarro $(2011 ; 2016)$ o Pécaut (2006), los que han alimentado parte de la legitimidad en el activismo guerrillero de las FARC-EP:

"Las FARC, tenían un interés en que hubiera mucha participación ciudadana, por razones obvias, de cómo entienden su relación con las bases, y nosotros, creyendo que la idea original de paz territorial, o por lo menos yo, entendiendo que la participación es necesaria para construir ese nuevo modelo de construcción de paz en Colombia” (Entrevista a Sergio Jaramillo, 2017).

Incluso, la participación se entiende como algo que debe trascender la dimensión política, al reivindicarse como de uno de los principios nucleares que sostienen y legitiman el Acuerdo en su totalidad, dado que la participación no ha de reducirse al punto uno y dos, que son los que condensan el mayor componente político, sino que igualmente afecta a la sustitución de cultivos o al conjunto de acciones que se necesitan para cumplir con los requerimientos de la justicia transicional y a reparación integral a las víctimas:

\footnotetext{
"Ese componente de participación está en todos los acuerdos, no solo en el punto 2 de participación, sino que está en el punto 1, en la mayor parte de las medidas, está en el punto 4 de sustitución de cultivos (...) y está en el tema de las víctimas, la reparación, la Comisión de la Verdad. Son todas. Pero el asunto no es solamente cómo hago yo participación. Se trata de participación bien hecha, en el sentido de una participación que pueda contribuir a la consecución de resultados. Esa participación tiene un valor en sí mismo" (Entrevista a Sergio Jaramillo, 2017).
}

No es casualidad, con base en lo anterior que Humberto de la Calle o Sergio Jaramillo, en ningún momento se detengan en entender la participación política como un problema a considerar sino más bien como un estímulo que debe afectar otras posibilidades de la relación de la sociedad civil con el 
Estado. Así, en este caso, más que como opción partidista, la participación política se traduce como una suerte de estímulo descentralizador que, de cierta manera, a partir de una óptica municipalista de mayor y mejor identificación y planificación respecto de las políticas públicas que afectan a los territorios más golpeados por la violencia:

"Los PDET tienen como destinatario comunidades pequeñas, en un proceso de participación y coordinación de los alcaldes pero que fundamentalmente tiene lugar en los pequeños territorios (...) luego ahí también me parece que tenemos un desafío que se incluye dentro del capítulo de la descentralización y que sí tendría que implicar también una reorganización y una nueva arquitectura de la administración territorial" (Entrevista a Humberto de la Calle, 2017).

De la misma manera, las FARC-EP coinciden en este punto con el Gobierno, al interpretar que la posibilidad de participación que permiten los PDET, si se implementa conforme a lo reconocido en el Acuerdo de Paz, implica una mejora sustancial en las bases de la democracia local colombiana:

"La metodología PDET es muy importante aquí. El enfoque debe ser territorial. Aquí, por ejemplo, nosotros hemos insistido en que, derechos ganados por las comunidades étnicas, como el de la consulta previa, deben permanecer. Porque la cosmovisión que tiene una comunidad indígena con respecto a cómo debe ser utilizado su territorio es diametralmente opuesta a la que puede tener la población colona o la población que maneja el país desde el centro" (Entrevista a "Jesús Santrich", 2017).

Frente a la posición más conservadora de reducir la participación a una dimensión electoral y conflictiva, las FARC-EP van incluso más allá del Gobierno y plantean que la participación política, a tenor de lo que recoge el Acuerdo, no se reduce a los territorios más golpeados por el conflicto armado y a los municipios. Lo más importante, en clave laclauniana, es visibilizar a las diferentes categorías sociales de la ciudadanía colombiana como mujeres, campesinos, indígenas o negritudes (Laclau y Mouffe, 1987) quienes, tradicionalmente, como señalan Wade (1993) o Restrepo y Rojas (2009), han sido los grandes olvidados del país. Por ejemplo, a tenor de que el Acuerdo de Paz prevé circunscripciones electorales (16) para que tengan representación directa en el Congreso, el número uno del equipo negociador de las FARC-EP, y excomandante del Bloque Caribe, "Iván Márquez", apunta lo siguiente:

"Tenemos pueblos indígenas, comunidades negras, sectores campesinos. Estamos imaginándonos un momento que va a ser determinante en la vida política del país, y es el momento en que, por primera vez, los territorios lleguen al Congreso, con sus botas untadas de barro. Cuando lleguen las caras plebeyas 
a participar en los debates nacionales sobre los asuntos más trascendentales que atañen con el destino de Colombia" (Entrevista a "Iván Márquez", 2017).

\section{Y el propio "Iván Márquez" continúa:}

"Las circunscripciones electorales transitorias, me estoy refiriendo a ellas, ha sido un logro muy importante y va a facilitar que estos sectores que nunca tuvieron voz, por primera vez puedan llegar al Congreso de la república. Son 16 circunscripciones. Claro que va a manifestarse, especialmente, en la Cámara de Representantes. Y digo que es un gran logro. Siempre hemos escuchado a las regiones" (Entrevista a "Iván Márquez", 2017).

Es decir, a tenor de lo expuesto, y de otros fragmentos recogidos de las narrativas de la jefatura del equipo negociador de las FARC-EP en el proceso de La Habana, se entiende que la participación política debe mejorar la propia impronta democrática del país pero también ha de modular hacia el futuro muchas de las estructuras del Estado colombiano que no pudieron ser integradas en el Acuerdo de Paz. Esto, en tanto que el mismo, en ningún momento invita a que la participación en política de las FARC-EP suponga en sí una ruptura con el sistema establecido, tal y como plantean las siguientes palabras de "Jesús Santrich":

"Nosotros publicamos siempre las propuestas mínimas, y que llevamos a la mesa. Y se llamaban mínimas porque no eran propuestas orientadas a hacer la revolución en la mesa. Era lo que se necesitaba, al menos, para lo que se denomina Estado Social de Derecho funcione, así sea en los términos liberales. No estábamos hablando en esos acuerdos de la revolución socialista, bolchevique. Ni mucho menos" (Entrevista a "Jesús Santrich", 2017).

Esto, en aras no solo de permitir la transformación política de las FARCEP de guerrilla a partido político, sino de permitir que las FARC-EP, como partido, tengan la posibilidad de disputar el poder político con garantías plenas a un proyecto de transformación democrática del Estado:

\footnotetext{
"Las FARC se van a convertir en un partido político, próximamente. Nosotros estamos trabajando ya las tesis de discusión. Y la discusión tendrá unos escenarios que son las 26 zonas de normalización. Estamos perfeccionado la idea que hemos lanzado al país de intención de un gobierno transicional (...) de una gran alianza política del país, de los sectores interesados en consolidar las bases para la paz estable y duradera a través de la implementación. Y de levantar unas banderas mínimas que aglutinen a la gente. (Entrevista a "Iván Márquez", 2017).
} 
Sin embargo, y como señala el Mayor General de la Policía Nacional, Ricardo Restrepo, para que eso tenga lugar no se puede pasar por alto el hecho de que resulta imprescindible garantizar seguridad y protección en el nivel político pues, sin ello, los derechos civiles y políticos carecen de condiciones mínimas para su correcto ejercicio:

\begin{abstract}
"Regresando a un proceso de paz, implementando los acuerdos, pues es casi la necesidad de que la Policía vuelva a su esencia. ¿Y cuál es su esencia? Precisamente, el servicio para con la comunidad. En este caso, el retorno de la Policía a lo que tiene que ver al campo. A lo rural. A un trabajo con el campesino, no solo a generarle la seguridad. No solo a combatir los fenómenos criminales que surjan a través o posteriores a un posconflicto, sino también a acompañar a ese campesino en todo lo que tiene que ver con el desarrollo rural" (Entrevista a Ricardo Restrepo, 2017).
\end{abstract}

\title{
6. Participación política sí... pero según el resultado de 2018
}

De acuerdo a lo planteado, para el conservadurismo, la participación política no solo es algo negativo para el sistema político colombiano, sino que además se trata de algo perfectamente revisable en el marco de las elecciones presidenciales de 2018. Con una posición de relativo reconocimiento al Acuerdo de Paz, para Marta Lucía Ramírez es deseable tener la posibilidad de discutir la revisión de este aspecto, incluso, politizándolo dentro de la misma campaña presidencial:

"Yo creo que, en todo caso, este Acuerdo ya produjo efectos que son irreversibles. Entonces, ¿uno cómo vuelve atrás a un punto cero si es que ya los efectos se produjeron y son irreversibles muchos de ellos? Yo lo que creo es que uno tiene que decir que aquí hay un Acuerdo que está en período de prueba. Dentro de 18 meses, el Gobierno que entre va a tener la posibilidad de volver otra vez a convocar al pueblo y decirle "hay cosas de este acuerdo que no se han desarrollado" y hay que ver si el pueblo colombiano está de acuerdo con ello. Para mí un punto de fondo es la participación en política". (Entrevista a Marta Lucía Ramírez, 2017).

Más lejos va Alejandro Ordóñez, cuando, como buena parte del conservadurismo más ortodoxo colombiano, reivindica la necesidad de poner fin al Acuerdo de Paz recurriendo a la falta de legitimidad resultante tras la derrota electoral del plebiscito el pasado octubre de 2016. Tanto es así, que cuando es preguntado por esto, señala lo siguiente:

"Yo estoy convencido de que estamos abocados a una Constituyente. Porque para combatir con eficacia toda la demolición institucional y la credibilidad que 
ha generado la corrupción y toda esta nueva institucionalidad que es ilegítima. Por qué es ilegítima no me detengo en ello. Requerimos a la mayoría holgada en la Presidencia y en el Congreso para lograr tramitar este proceso constituyente. Que llegado el caso pueda revertir los acuerdos de La Habana. Los acuerdos de La Habana no están blindados como creen". (Entrevista a Alejandro Ordóñez, 2017).

Tanto uno como otro recurren a un argumento de desconfianza a priori con respecto del compromiso de las FARC-EP por dejar las armas y asumir un verdadero y efectivo proceso de dejación de armas y reincorporación. Así, sobre la base de recurrir a la negación de lo anterior, con independencia de valorar objetivamente cualquier avance o cumplimiento de parte de la guerrilla es que se justifica la revisión del compromiso de paz suscrito:

“¿Las FARC se van a desmovilizar?, ¿las FARC van a entregar las armas?, ¿los milicianos se van a desmovilizar?, ¿van a dejar el narcotraficar?, ¿van a dejar a reparar las víctimas? Es eso lo que hay que preguntar. ¿Van a entregar los niños? Entonces si las FARC no hacen eso, ¿qué hacer? ¿Qué le corresponde a un gobernante? El gobernante debe decir, si ustedes no hacen eso, que es lo mínimo, entonces hay que ver. Yo creo que Trump los recibe (por la extradición) con las cárceles abiertas (Entrevista a Alejandro Ordóñez, 2017).

\section{Y algo parecido añade Marta Lucía Ramírez:}

"Creo que lo que tanto advertimos durante el proceso de negociación con las FARC ya es evidente. Se está dando el cambio de brazaletes. Hay unos ejércitos armados que son como mercenarios. Que están dispuestos a ponerse el brazalete que sea porque esto no funciona con una ideología" (Entrevista a Marta Lucía Ramírez, 2017).

Este tipo de posicionamientos implican una serie de riesgos que son advertidos como una amenaza para el equipo de Gobierno actual, en tanto que la participación política, por un lado, no puede cuestionarse como algo a dejar por fuera del Acuerdo suscrito con las FARC, y mucho menos puede motivar una disputa electoral basada en un clivaje cumplimiento del Acuerdo Sí/No:

"El Estado colombiano debe cumplir lo que se pactó con las FARC. Yo tengo una enorme preocupación cuando empiezo a oír voces que, de incluso, de alguna manera, quieren virtualmente repetir el plebiscito del 2 de octubre, en el año 2018, con la promesa de que, si gana lo que fue el No en su momento, entonces, habría que revisar los acuerdos. Eso me parece realmente un error histórico fundamental" (Entrevista a Humberto de la Calle, 2017).

Incluso, podría decirse que sobre este aspecto de la irreversibilidad del Acuerdo resulta mucho más evidente la posición de las Fuerzas Militares. Tal y 
como reconoce uno de los responsables del equipo negociador en La Habana, como es el Mayor General Rojas:

\begin{abstract}
"Arrancando ese proceso de dejación de las armas que yo creo que va a consolidar mucho este proceso de paz. Va a mostrar un compromiso verdadero de las FARC por continuar con este proceso de paz. Y al país, a la sociedad, que está escéptica, le va a mostrar que el proceso de paz sí funciona y avanza hacia una consolidación que no tiene marcha atrás. Yo diría que ya, en este momento, el proceso es irreversible. Yo lo diría en este momento. Pero cuando se dé la entrega de armas ya no habrá duda alguna de que es un proceso irreversible". (Entrevista a Carlos Rojas, 2017).
\end{abstract}

Sergio Jaramillo se posicionaría, por ejemplo, en la antítesis de lo expuesto por Marta Lucía Ramírez cuando ésta habla de transitoriedad. Es decir, la transitoriedad no es el período, como entienden los enemigos del Acuerdo de Paz, entre la ratificación al mimo por parte de los poderes del Estado, bajo la bandera del actual Gobierno de Juan Manuel Santos y las elecciones de la próxima primavera. La transición en sí, es el Acuerdo y éste debe ser ese impasse entre la superación de la violencia directa, lo cual Galtung (1969) denomina como paz negativa, y la superación de las condiciones estructurales que soportan la violencia, y que por lo general comprenden el concepto de paz positiva. Dicho de otro modo, el período de implementación del Acuerdo no se puede plantear bajo condicionamientos gubernamentales en tanto que se trata de una política de Estado:

\begin{abstract}
"Para que el tema de paz territorial tenga sostenibilidad en el tiempo, y esto es otra dimensión, habría que empezar más allá de la negociación de La Habana y lo que uno pueda corregir, cuáles son los elementos estructurales que van a permitir eso. (...) . Los acuerdos tienen que ir más allá para asentar las bases de esa paz estable y duradera que es lo que dice el Acuerdo Final". (Entrevista a Sergio Jaramillo, 2017).
\end{abstract}

Una posición cercana tienen las FARC-EP cuando son preguntadas sobre el escenario de incertidumbre que acompaña a las elecciones presidenciales de la primavera de 2018. Incertidumbres en la medida en que otros líderes políticos, además de los entrevistados Alejandro Ordóñez o Marta Lucía Ramírez, plantean la hipótesis de la reversibilidad total o parcial del Acuerdo de Paz, tal y como sucede con Álvaro Uribe o con Germán Vargas Lleras exvicepresidente durante siete años de Juan Manuel Santos:

\footnotetext{
"Aquí hay problema de casta política y hemos dicho, aquí un gran problema es la renegociación que se está haciendo de los acuerdos. Es decir, que cada quien pretende desde el Congreso, ni siquiera de forma sino de fondo a lo que está acordado" (Entrevista a "Jesús Santrich", 2017).
} 
Es decir, la participación política inmediata correspondería al Gobierno en relación con proteger y desarrollar el Acuerdo de Paz a efectos de hacer visible cuánto necesario es transformar buena parte de las estructuras sociales, económicas, políticas, culturales e institucionales del Estado colombiano. Solo así es que se puede despolitizar el rédito electoral que sobre él proponen las voces críticas al proceso:

\footnotetext{
"Si realmente Santos cumple con esto, creo que se van a generar condiciones ideales para buscar mediante una alianza política sólida, que la implementación se convierta en una realidad" (Entrevista a "Iván Márquez", 2017).
}

No obstante, al respecto se aprecia una postura mucho más ortodoxa en "Jesús Santrich", al distinguir entre la potencialidad transformadora del Acuerdo y la realidad en cuanto a su implementación, que de llegar sin cumplirse a 2018, puede favorecer la posibilidad de posiciones revisionistas con respecto del mismo:

\begin{abstract}
"Pero eso no se ha podido resolver porque estamos como en una etapa, no de implementación, sino de renegociación, y eso es muy dramático, porque el Congreso debería estar en sintonía y ahora cada quien está en que quiere poner una proposición y engancharle su particular punto de vista a los acuerdos y se ha intentado renegociar no solo con el Congreso, sino con los militares, y con los jueces” (Entrevista a "Jesús Santrich”, 2017).
\end{abstract}

\title{
7. Conclusiones
}

Los Acuerdos de Paz, tal y como se han presentado en relación a la participación política podría decirse que son una especie de ley kantiana en tanto que integran la obligación de realizar un acto al que nadie puede ser obligado (Kant, 1795). Sin embargo, ese carácter contradictorio no impide que sea honesta. La participación política, del modo en que se inscribe en el Acuerdo implica un cambio institucional, territorial, político-partidista y político-social que invita a reconocer que la democracia colombiana, tal y como ha llegado al siglo XXI, tras más de cinco décadas de conflicto armado interno - y aún con el proceso abierto con la guerrilla del ELN- necesita se repensado y rediseñado.

$\mathrm{Al}$ respecto, las narrativas que se han identificado se deslizan a través de diversos discursos que, a su vez, abarcan, al menos conforme a tres discursos políticos.

- Por un lado, la oposición más reaccionaria al Acuerdo no respalda ninguno de los sentidos de la participación política que conlleva el mismo. En primer lugar, no reconocen en ningún momento la legitimidad 
del discurso de las FARC-EP de modo que su conversión legal partidista contravendría el propio espíritu del Estado de Derecho y, por extensión, del orden constitucional. Asimismo, entienden que el empoderamiento territorial de los enclaves más golpeados por la guerrilla, más que profundizar en una mejor democracia, supone conceder soberanía y poder a la guerrilla para que continúe en la criminalidad. Las nuevas posibilidades de participación ciudadana son interpretadas en clave de amenaza, desorden y afectación negativo al status quo de modo que continuamente se justifica la necesidad de revisar este aspecto a tenor del escenario electoral presidencial que se va a dar en Colombia en la primavera de 2018.

- $\quad$ Por otro lado, desde el equipo negociador, el cual representa la posición gubernamental, se reconoce la participación política de las FARC-EP como necesaria dentro del nuevo escenario político que para Colombia debe suponer el Acuerdo, si bien el énfasis se centra en la importancia del resto de niveles de participación. Es decir, entender la participación, sobre todo, como un ejercicio de incorporar a los territorios tradicionalmente olvidados por el conflicto armado, por medio del proceso de municipalización que representan los PDET, y como una forma de nuevas representaciones y posibilidades para la ciudadanía, lo cual, junto a lo anterior, contribuye a mejorar una democracia que, al menos, tácitamente se reconoce como débil en algunos aspectos. De igual manera, esta posición considera que el Acuerdo es legítimo en sí mismo y no solo no debe abrirse la posibilidad de cuestionarse, sino que en tanto que se trata de una política de Estado y no de Gobierno, el Ejecutivo que suceda a Juan Manuel Santos en 2018 tiene el imperativo de conferir continuidad a lo acordado con la guerrilla.

- Finalmente, las FARC-EP plantean una narrativa mucho más crítica y radical con la participación política. Además de reiterar la necesidad del tránsito de las armas a las urnas, conectan esa participación política como la única manera de visibilizar problemáticas desatendidas durante décadas por el conflicto armado. Entienden que la democracia local debe de proyectar especial interés sobre estas regiones y que, igualmente, se debe hacer dando voz a cosmovisiones tradicionalmente opacadas, como son las provenientes del escenario rural colombiano y de mujeres, afrodescendientes e indígenas, lo cual aproxima de algún modo esta noción a la idea de democracia radical laclauniana. Por otro lado, interpretan que la participación, y por extensión, la oposición política ha de ser no solo en clave política sino en clave social y, por ende, es que aprueban las posibles nuevas formas de conflictividad y protesta social que deben sustantivar el sistema político colombiano tras la 
implementación del Acuerdo de Paz. Como sería de esperar, comparten la interpretación del Gobierno de que los compromisos adquiridos son irrevocables si bien reclaman que, de cierto modo, dicha irreversibilidad depende de la consolidación de los mismos en cuanto a implementación y desarrollo de lo acordado.

Cada uno de los discursos incorpora, por tanto, la noción de participación política, pero la incluye en narrativas diferentes. De modo que la participación política no es sólo un concepto relativamente oscuro, sino también polisémico en su aplicación al proceso de paz colombiano. 


\section{Referencias bibliográficas:}

Acemoglu, D; Robinson, J. y Santos, R. (2013). The monopoly of violence: Evidence from Colombia. Journal of the European Economic Association, 11(1), 5-44.

Ariño, A. (1997). Ideologías, discursos y dominación. Revista Española de Investigaciones Sociológicas, 79, 197-219.

Barzelay, M. y Cortázar, J. C. (2004). Una guía práctica para la elaboración de estudios de caso sobre buenas prácticas en gerencia social. Washington: INDES.

Becker, W. (1990). La libertad que queremos: la decisión para la democracia liberal. México D.F.: Fondo de Cultura Económica.

Bejarano, A. Ma. (2011). Democracias precarias. Trayectorias políticas divergentes en Colombia y Venezuela. Bogotá: Universidad de Los Andes.

Bencardino, J. (2014). Construcción de paz y un nuevo modelo de construcción de estado. Una lectura de los dos primeros acuerdos de La Habana. Revista de Economía Institucional, 16(30), 131-169.

Berdal, M. y Ucko, D. H. (2009). Reintegrating armed groups after conflicto: Politics, violence and transition. Abingdon: Routledge.

Burton, J. (1990). Conflict: Resolution and Provention. Nueva York: St. Martin's Press.

Bushnell, D. (2007). Colombia: una nación a pesar de sí misma. Bogotá: Planeta.

Cairo, H; Oslender, U; Piazzini Suárez, C. E; Ríos, J; Koopman, S; Montoya Arango, V; Rodríguez Muñoz, F. B. \& L. Zambrano (2018). “'Territorial Peace': The Emergence of a Concept in Colombia's Peace Negotiations", Geopolitics, DOI: 10.1080/14650045.2018.1425110

Centro Nacional de Memoria Histórica. (2013). ¡Basta Ya! Colombia: Memorias de guerra y dignidad. Bogotá: CNMH.

Clausewitz, C. ([1832]2010) De la guerra. Madrid: Tecnos.

Denissen, M. (2010). Reintegrating excombatants into civilian life: The case of the paramilitaries in Colombia. Peace \& Change, 35(2), 328-352.

Dukes, F. (1999). Structural Forces in Conflict and Conflict Resolution in Democratic Society. En H. Won Jeong (ed.). Conflict Resolution: Dynamics, Process and Structure (pp. 155-172). Brookfield: Ashgate.

Edeleman, M. (1991). La construcción del espectáculo político. Buenos Aires: Manantial.

Fisas, V. (2002). Cultura de paz y gestión de conflictos. Barcelona: Icaria.

Fisas, V. (2004). Procesos de paz y negociación en conflictos armados. Barcelona: Paidós. 
Foucault, M. (1976). Defender la sociedad. Curso en el Collège de France (1975-1976). México, D.F.: Fondo de Cultura Económica.

Galtung, J. (1969). Violence, peace and peace research. Journal of Peace Research, 6(3), 167-191.

Galtung, J. (1985). Sobre la paz. Barcelona: Fontamara.

Galtung, J. (1998). Tras la violencia, 3R: reconstrucción, reconciliación, resolución. Afrontando los efectos visibles e invisibles de la guerra y la violencia. Bilbao: Gernika Gogoratuz.

Geertz, C. (1987). La interpretación de las culturas. Barcelona: Gedisa.

Guelke, A. (2012). Politics in deeply divided societies. Cambridge: Polity Press. Habermas, J (1987). Teoría de la acción comunicativa. Madrid: Taurus.

Habermas, J (1999). La inclusión del otro. Estudios de teoría política. Barcelona: Paidós.

Harbom, L; Högbladh, S. y Wallensteen, P. (2006). Armed Conflict and Peace Agreements. Journal of Peace Research, 43(5), 617-631.

Harto, F. (2004). Investigación para la paz y resolución de conflictos. Valencia: Tirant Lo Blanch.

Harto, F. (2013). "La mediación y la investigación para la paz: la búsqueda de alternativas pacíficas a los conflictos en la arena internacional". Política y Sociedad, 50(1), 53-70.

Jarstad, A. y Sisk, T. (2008). From war to democracy: Dilemmas of peacebuilding. Cambridge: Cambridge University Press.

Jiménez, F. (2014). Paz neutra: una ilustración del concepto. Revista de Paz y Conflictos, 7, 19-52.

Kant, I. ([1795]2003). La paz perpetua. Madrid: Alianza.

Kymlicka, W. (1996). Ciudadanía multicultural. Barcelona: Paidós.

Laclau, E. y Mouffe, C. (1987). Hegemonía y estrategia socialista. Hacia una radicalización de la democracia. Madrid: Siglo XXI.

Lanza, J. (2017). El método narrativo para entenderla trayectoria y el funcionamiento de las políticas públicas locales. Ciencia Política, 12(23), 175-203.

Lederach, J. P. (1997). Building Peace. Sustainable Reconciliation In Divided Societies. Washington: USIP Press.

Lederach, J. P. (2005). The Moral Imagination. The Art and Soul of Building Peace. Oxford: Oxford University Press.

Mason, D.; Crenshaw, M.; McClintock, C. y Walter, B. (2007). How Political Violence Ends: Paths to Conflict Deescalation and Termination. APSA Task Force on Political Violence and Terrorism, Group 3. [En línea]. Disponible en: http://www.apsanet.org/imgtest/PVTFHowPoliticalViolenceEnds.pdf. [Consultado el 7 de julio de 2017]. 
Miall, H.; Mitchell, C.; Rambsbotham, O. y Woodhouse, T. (2015). The Contemporary Conflict Resolution Reader. Cambridge: Polity Press.

Pécaut, D. (2006). Crónica de cuatro décadas de política colombiana. Bogotá: Norma.

Pizarro, E. (2011). Las FARC (1949-2011). De guerrilla campesina a máquina de guerra. Bogotá: Norma.

PNUD. (2004). La democracia en América Latina. Hacia una democracia de ciudadanos y ciudadanas. Nueva York: Naciones Unidas.

Prokkola, E-K. (2014). Using Narrativity as Methodological Tool. ACME: An International E-Journal for Critical Geographies, 13(3), 442-449.

Restrepo, E. y Rojas, A. (2004). Conflicto e (in)visibilidad: retos de los estudios de la gente negra en Colombia. Popayán: Universidad de Cauca.

Ríos, J. (2017). Breve historia del conflicto armado en Colombia. Madrid: Los Libros de La Catarata.

Ríos, J. (2017). "El Acuerdo de Paz entre el Gobierno colombiano y las FARC: o cuando una paz imperfecta es mejor que una guerra perfecta". Araucaria. Revista Iberoamericana de Política, Filosofía y Humanidades, 19(38), 593-618.

Robinson, J. A. (2016) La miseria en Colombia. Desarrollo y Sociedad, 76, 9-90.

Sandole, D. y Sandole, I. (1987). Conflict management and problem solving: interpersonal to international applications. Londres: London F. Pinter.

Taylor, L. (2016). Impact of political violence, social trust and depression on civic participation in Colombia. Peace and conflict, 22(2), 145-152.

Ugarriza, J. E. (2013). La dimensión política del posconflicto: discusiones conceptuales y avances empíricos. Colombia Internacional, 77, 141-176.

Van Dijk, T. A. (2004). Discurso y dominación. Grandes Conferencias en la Facultad de Ciencias Humanas, 4, 5-28.

Van Dijk, T. A. (2005). Ideología y análisis del discurso. Revista Utopía y Praxis Latinoamericana, 29, 9-36.

Wade, P. (1993). Blackness and Race Mixture: The Dynamics of Racial Identity in Colombia. Baltimore: Johns Hopkins University Press.

Wallensteen, P. (2010). Understanding conflict resolution. Boulder: Lynne Rienner. 
